\title{
An in vitro comparison of tracheostomy tube cuffs
}

This article was published in the following Dove Press journal:

Medical Devices: Evidence and Research

2I April 2015

Number of times this article has been viewed

\section{Seamus Maguire \\ Frances Haury ${ }^{2}$ \\ Korinne Jew ${ }^{2}$}

'Research and Development, Covidien Respiratory and Monitoring Solutions, Athlone, Ireland; ${ }^{2}$ Medical Affairs, Covidien Respiratory and Monitoring Solutions, Boulder, CO, USA
Correspondence: Korinne Jew Medical Affairs, Covidien Respiratory and Monitoring Solutions, 6135 Gunbarrel Avenue, Boulder, CO 80304, USA

$\mathrm{Tel}+\mathrm{I} 3033052509$

Fax + I 3033052246

Email kori.jew@covidien.com
Introduction: The Shiley ${ }^{\mathrm{TM}}$ Flexible adult tracheostomy tube with TaperGuard ${ }^{\mathrm{TM}}$ cuff has been designed through its geometry, materials, diameter, and wall thickness to minimize microaspiration of fluids past the cuff and to provide an effective air seal in the trachea while also minimizing the risk of excessive contact pressure on the tracheal mucosa. The cuff also has a deflated profile that may allow for easier insertion through the stoma site. This unique design is known as the TaperGuard ${ }^{\mathrm{TM}}$ cuff. The purpose of the observational, in vitro study reported here was to compare the TaperGuard ${ }^{\mathrm{TM}}$ taper-shaped cuff to a conventional high-volume low-pressure cylindrical-shaped cuff (Shiley ${ }^{\mathrm{TM}}$ Disposable Inner Cannula Tracheostomy Tube [DCT]) with respect to applied tracheal wall pressure, air and fluid sealing efficacy, and insertion force.

Methods: Three sizes of tracheostomy tubes with the two cuff types were placed in appropriately sized tracheal models and lateral wall pressure was measured via pressure-sensing elements on the inner surface. Fluid sealing performance was assessed by inflating the cuffs within the tracheal models $\left(25 \mathrm{cmH}_{2} \mathrm{O}\right)$, instilling water above the cuff, and measuring fluid leakage past the cuff. To measure air leak, tubes were attached to a test lung and ventilator, and leak was calculated by subtracting the average exhaled tidal volume from the average delivered tidal volume. A tensile test machine was used to measure insertion force for each tube with the cuff deflated to simulate clinical insertion through a stoma site.

Results: The average pressure exerted on the lateral wall of the model trachea was lower for the taper-shaped cuff than for the cylindrical cuff under all test conditions $(P<0.05)$. The tapershaped cuff also demonstrated a more even, lower pressure distribution along the lateral wall of the model trachea. The average air and fluid seal performance with the taper-shaped cuff was significantly improved, when compared to the cylindrical-shaped cuff, for each tube size tested $(P<0.05)$. The insertion force for the taper-shaped cuff was $\sim 40 \%$ less than that for the cylindrical-shaped cuff.

Conclusion: In a model trachea, the Shiley ${ }^{\mathrm{TM}}$ Flexible Adult tracheostomy tube with TaperGuard $^{\mathrm{TM}}$ cuff, when compared to the Shiley ${ }^{\mathrm{TM}}$ Disposable Inner Cannula Tracheostomy tube with cylindrical cuff, exerted a lower average lateral wall pressure and a more evenly distributed pressure. In addition, it provided more effective fluid and air seals and required less force to insert.

Keywords: airway device, air seal, fluid seal, taper-shaped cuff, intra-cuff pressure, cuff pressure

\section{Introduction}

High-volume low-pressure (HVLP) cuffs, on both endotracheal and tracheostomy tubes, have been the predominant cuff type used to create a seal between the tube shaft and the tracheal wall of patients for many years. The primary feature of a HVLP cuff is a 
large diameter and a large residual volume such that the cuff resting diameter is larger than the patient's tracheal diameter. The intra-cuff pressure of an un-stretched HVLP cuff correlates closely with the tracheal wall pressure, which is not the case for low-volume cuffs. ${ }^{1,2}$ In order to ensure that the wall of the cuff is not stretched during use, the cuff resting diameter must be greater than the tracheal diameter. Another important characteristic of HVLP cuffs is the thin compliant wall material that, when inflated, adapts and conforms easily to the topography of the trachea wall. This cuff technology was developed several decades ago and in vivo experiments as well as clinical studies have demonstrated the effectiveness of HVLP cuffs at creating low-pressure seals in the trachea. ${ }^{3}$ Research has also demonstrated that, when inflated, HVLP cuffs, which are traditionally cylindrical shaped, form longitudinal folds with micro-channels that allow for the direct passage of air and fluid past the cuff. ${ }^{4-6}$

While the intra-cuff pressure of un-stretched HVLP cuffs correlates closely with the pressure applied to the tracheal wall, patient complications can still occur when excessive pressure is exerted on the tracheal wall that may damage the tracheal mucosa. These complications can be attributed to over inflation of the cuff or, as demonstrated in this study, to poor cuff design and the use of excessively rigid cuff materials. In theory, a HVLP cuff constructed of an infinitely flexible material will conform perfectly to the wall of the trachea, creating pressure on the tracheal wall that equals the intra-cuff pressure. In practice, however, cuff material is not infinitely flexible and, therefore, there will be areas of contact and noncontact between the wall of the trachea and the cuff because the intra-cuff pressure is not sufficient to overcome the rigidity of the cuff. This intermittent contact will create areas of higher and lower contact pressure. ${ }^{7}$ Traditional tracheostomy tubes, including the Shiley ${ }^{\mathrm{TM}}$ Disposable Inner Cannula tracheostomy (DCT) tube, have a cylindrical-shaped HVLP cuff (Figure 1A and B).

Significant advancements have been made in cuff design to overcome deficiencies in the performance of traditional HVLP cuffs. The Shiley ${ }^{\text {TM }}$ Flexible Adult tracheostomy tube

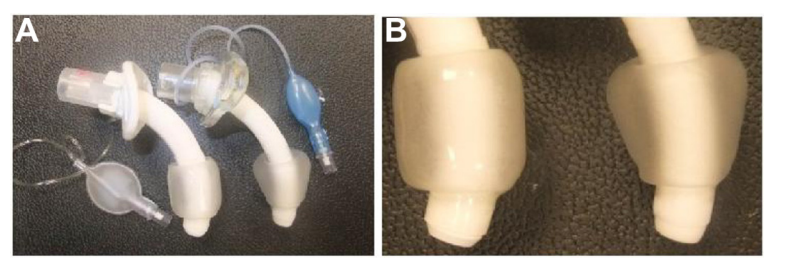

Figure I (A) Shiley ${ }^{\mathrm{TM}}$ Disposable Cannula tracheostomy (DCT) tube with cylindrical cuff (left) and Shiley ${ }^{\mathrm{TM}}$ Flexible tracheostomy tube with TaperGuard ${ }^{\mathrm{TM}}$ cuff (right). (B) Shiley ${ }^{\mathrm{TM}}$ DCT tube cylindrical cuff (left) and TaperGuard ${ }^{\mathrm{TM}}$ cuff (right). has a taper-shaped TaperGuard ${ }^{\mathrm{TM}}$ cuff which is constructed from a thinner, more compliant, and lower friction material than that used for the predecessor Shiley ${ }^{\mathrm{TM}}$ tracheostomy tube line, with a geometry designed to seal more effectively. A lower friction surface may also promote a more effective seal because friction between the cuff and tracheal wall might lead to the formation of folds in the cuff. ${ }^{7}$

Studies of the TaperGuard ${ }^{\mathrm{TM}}$ cuff in endotracheal tubes have demonstrated that the smaller-volume TaperGuard ${ }^{\mathrm{TM}}$ cuff, with its reduced tracheal contract area, can effectively seal the trachea. ${ }^{8,9}$ However, assessment of the pressures at which this effective seal is achieved in tracheostomy tubes has not been undertaken. In addition, comparison between tracheostomy tubes having the DCT tube cylindrical-shaped and TaperGuard ${ }^{\mathrm{TM}}$ taper-shaped cuffs has not been made. Therefore, bench tests were performed to compare the new Shiley ${ }^{\mathrm{TM}}$ Flexible Adult tracheostomy tube with the TaperGuard $^{\mathrm{TM}}$ cuff to the Shiley ${ }^{\mathrm{TM}}$ DCT tube with cylindrical cuff with respect to lateral wall pressure, air seal performance, fluid seal performance, and insertion force.

\section{Methods}

\section{Lateral wall assessment}

The lateral wall pressure test was performed to compare the average pressure exerted by each cuff type at its point of contact with the lateral wall of a model trachea. In addition, the pressure profile exerted by each cuff type against the tracheal model wall was also examined.

The smallest $(6.5 \mathrm{~mm})$, midrange $(7.5 \mathrm{~mm})$, and largest $(10.0 \mathrm{~mm})$ internal-diameter (ID) models of the adult tracheostomy tubes were tested to ensure that the extreme, as well as the most commonly used, sizes were included. The Shiley ${ }^{\mathrm{TM}}$ DCT tubes, which use the Jackson sizing system, were matched to the Shiley ${ }^{\mathrm{TM}}$ Flexible tubes which use the International Organization for Standardization sizing system. Table 1 lists the dimensions of the tubes and the sizes of the model tracheas in which they were tested.

Polycarbonate model tracheas with pressure sensors mounted on the inner surface were used. Three model tracheas were constructed for use with each tube size having internal diameters of $18.0 \mathrm{~mm}, 20.5 \mathrm{~mm}$, and $22.5 \mathrm{~mm}$. The pressure-sensing strips mounted on the model tracheas contained multiple individual elements that generated an electrical response in proportion to the pressure applied to that element. This pressure-mapping system contained the electronic hardware necessary to amplify the signal from the array which was then transmitted to a computer for further processing and analysis by Chameleon TVRTM software version 1.6.2.0 (Pressure Profile Systems, Los Angeles, 
Table I Dimensions of tracheostomy tubes and model tracheas

\begin{tabular}{|c|c|c|c|c|}
\hline $\begin{array}{l}\text { Tube } \\
\text { ID (mm) }\end{array}$ & $\begin{array}{l}\text { Tube } \\
\text { OD }(\mathrm{mm})\end{array}$ & $\begin{array}{l}\text { Model trachea } \\
\text { ID }(\mathrm{mm})\end{array}$ & Product type & $\begin{array}{l}\text { Product cuff } \\
\text { OD }(\mathrm{mm})\end{array}$ \\
\hline \multirow[t]{2}{*}{6.5} & 9.4 & 18.0 & Shiley ${ }^{\mathrm{TM}}$ Flexible tube with TaperGuard ${ }^{\mathrm{TM}}$ cuff & 20.6 \\
\hline & & & Shiley ${ }^{\mathrm{TM}}$ DCT tube with cylindrical cuff & 20.0 \\
\hline \multirow[t]{2}{*}{7.5} & 10.8 & 20.5 & Shiley ${ }^{\mathrm{TM}}$ Flexible tube with TaperGuard ${ }^{\mathrm{TM}}$ cuff & 25.4 \\
\hline & & & Shiley ${ }^{\mathrm{TM}}$ DCT tube with cylindrical cuff & 24.0 \\
\hline \multirow[t]{2}{*}{10.0} & 13.8 & 22.5 & Shiley ${ }^{\mathrm{TM}}$ Flexible tube with TaperGuard ${ }^{\mathrm{TM}}$ cuff & 28.6 \\
\hline & & & Shiley TM DCT tube with cylindrical cuff & 29.0 \\
\hline
\end{tabular}

Abbreviations: DCT, Disposable Cannula tracheostomy; ID, inner diameter; OD, outer diameter.

CA, USA). Each tube was inserted into the corresponding model trachea and the average pressure was measured at contact points between the cuff and model trachea along the cuff profile. The tracheal wall pressure was measured for each size tracheostomy tube as cuff inflation was increased in a stepwise fashion from 0 to 10,20 , and $30 \mathrm{cmH}_{2} \mathrm{O}$ pressure. Each test was performed on ten samples of each product type. The test method used a rigid model trachea which did not expand, allowing the pressure applied by the cuff to be captured without variability in the rate and degree to which a flexible model may respond to the force applied, thus adding noise into the measurement system. In addition, current "state of the art" low-pressure sensors do not expand, therefore, it was not practical to perform this test using a soft, flexible model trachea.

The average pressure exerted by each cuff type was quantified and the pressure distribution was qualitatively assessed and graphically represented using a high-resolution pressure-sensing array. This assessment was performed on the $7.5 \mathrm{~mm}$ Shiley ${ }^{\mathrm{TM}}$ Flexible tracheostomy tube, with the TaperGuard ${ }^{\mathrm{TM}}$ cuff and a size 6 Shiley $^{\mathrm{TM}}$ DCT tube with cylindrical cuff. This design enabled the examination of the smaller contact band of the taper-shaped cuff compared to the larger contact area of the HVLP cuff. All experiments were conducted according to an internally created cuffpressure-mapping protocol.

\section{Air seal assessment}

The purpose of this test was to determine the efficacy of the tracheostomy tube cuffs at creating a seal with the trachea to prevent air leakage past the cuff to the atmosphere. Tracheostomy tubes were connected to a ventilator via a breathing circuit to simulate the cyclic air flow applied to the cuff during routine use. Tracheostomy tubes of each size were placed into a rigid acrylic tracheal model attached to a Dual Adult Test Lung test lung (Michigan Instruments, Grand Rapids, MI, USA). The tracheostomy tube cuff was inflated and the tube connected to a Puritan Bennett 760 ventilator (Covidien, Carlsbad, CA, USA) via a breathing circuit. Ventilator settings were as follows: pressure control, inspiratory pressure $15 \mathrm{cmH}_{2} \mathrm{O}$; respiratory rate, 20 breaths per minute; inspiratory to expiratory time ratio, 1:2; rise time, $70 \mathrm{~ms}$; positive end-expiratory pressure, $5 \mathrm{cmH}_{2} \mathrm{O}$; sensitivity, $15.2 \mathrm{~L} / \mathrm{min}$; and oxygen, $21 \%$. The cuff was inflated to $25 \mathrm{cmH}_{2} \mathrm{O}$ via a cuff inflation system attached to a digital pressure manometer which allowed for continuous cuff pressure monitoring and adjustment. The compliance of the test lung was adjusted to obtain an exhaled tidal volume of $330-338 \mathrm{~mL}$ for $6.5 \mathrm{~mm}$ tubes and $495-505 \mathrm{~mL}$ for other tube sizes. Tidal volume ranges were based on the average predicted body weight of the patients in which tubes are used. It is recommended that adult females and males should receive, at least initially, tracheostomy tubes with outer diameters of $10 \mathrm{~mm}$ and $11 \mathrm{~mm}$, respectively. ${ }^{10}$ Therefore, a $55 \mathrm{~kg}$ female would receive a $6.5 \mathrm{~mm}$ tube and, when ventilated at $6-8 \mathrm{~mL} / \mathrm{kg}$, have an expected tidal volume of $\sim 330 \mathrm{~mL}$ (eg, a $75 \mathrm{~kg}$ male ventilated at $6-8 \mathrm{~mL} /$ $\mathrm{kg}$ would have a tidal volume of $\sim 500 \mathrm{~mL}$ ). Thirty samples of each tube type were tested. The system was stabilized for 60 seconds, after which time five breaths were recorded. The average exhaled volume was subtracted from the average delivered volume as measured by the ventilator. The delta between average exhaled volume and average delivered volume is the loss in air past the cuff.

\section{Fluid seal assessment}

The purpose of this test was to determine the efficacy of the tracheostomy tube cuffs to create a seal with the trachea to prevent the passage of fluid past the cuff. A tracheostomy tube was inserted into an acrylic trachea and the cuff inflated to $25 \mathrm{cmH}_{2} \mathrm{O}$ while the tracheal model was maintained in a $37^{\circ} \mathrm{C}-39^{\circ} \mathrm{C}$ water bath for $15-30$ minutes. A distilled water reservoir at $37^{\circ} \mathrm{C}-39^{\circ} \mathrm{C}$ was maintained $2.0-2.4 \mathrm{~cm}$ above the proximal cuff via a siphon tube for 10 minutes. Any water able to leak past the cuff was collected in a beaker under the model trachea. The weight of the water was used to calculate the leak. 


\section{Ease of insertion assessment}

The insertion-force bench test assessed the maximum force required to insert a deflated cuffed tracheostomy tube through an artificial stoma opening. The artificial stoma consisted of a synthetic latex sheet $0.49 \mathrm{~mm}$ thick with an incision $30 \mathrm{~mm}$ long. The sheet was held taut within a support fixture. An Instron ${ }^{\circledR}$ Tensile Test Machine (Instron ${ }^{\circledR}$, Norwood, MA, USA) was used to measure and record the insertion force.

\section{Statistical analysis}

Two-sample $t$-tests were performed to detect differences between cuff types in terms of lateral wall pressure, fluid and air leak, and mean insertion force for each tube size. Data are summarized as mean and standard deviation.

\section{Results}

\section{Lateral wall pressure}

The relationship between the intra-cuff pressure and the pressure applied by the cuff to the model trachea wall is shown for each tracheostomy tube size in Figure 2A-C.

For each tube size, the average pressure exerted on the lateral wall of the model trachea was lower for the
Shiley ${ }^{\mathrm{TM}}$ Flexible tube with TaperGuard ${ }^{\mathrm{TM}}$ cuff than for the Shiley ${ }^{\mathrm{TM}}$ DCT tube with the cylindrical-shaped cuff. As tube size increased, so did the difference between the cuff types in terms of pressure applied to the tracheal wall, with applied pressure differences reaching $\sim 10 \mathrm{cmH}_{2} \mathrm{O}$ at each intra-cuff pressure for the largest tracheostomy tube sizes (Figure 2C).

Graphical representations of the pressure array exerted by the $7.5 \mathrm{~mm}$ Shiley ${ }^{\mathrm{TM}}$ Flexible tracheostomy tube with the TaperGuard ${ }^{\mathrm{TM}}$ cuff and a size 6 Shiley ${ }^{\mathrm{TM}}$ DCT with cylindrical cuff on the lateral wall of the model trachea are shown in Figure 3, with the cuffs inflated to increasing intra-cuff pressures from 0 to $30 \mathrm{cmH}_{2} \mathrm{O}$. As stated earlier, it is widely accepted that, for un-stretched HVLP cuffs, the intra-cuff pressure will correlate closely with tracheal wall pressure. This was found to be true when the quantitative analysis was performed, as shown in Figure 2. However, deviations from the expected 1:1 relationship between the intra-cuff pressure and the pressure applied to the tracheal wall are also apparent. The graphical representation in Figure 3 demonstrates that, given that materials are not infinitely flexible, there will be points of contact and noncontact between the cuff and the model trachea.

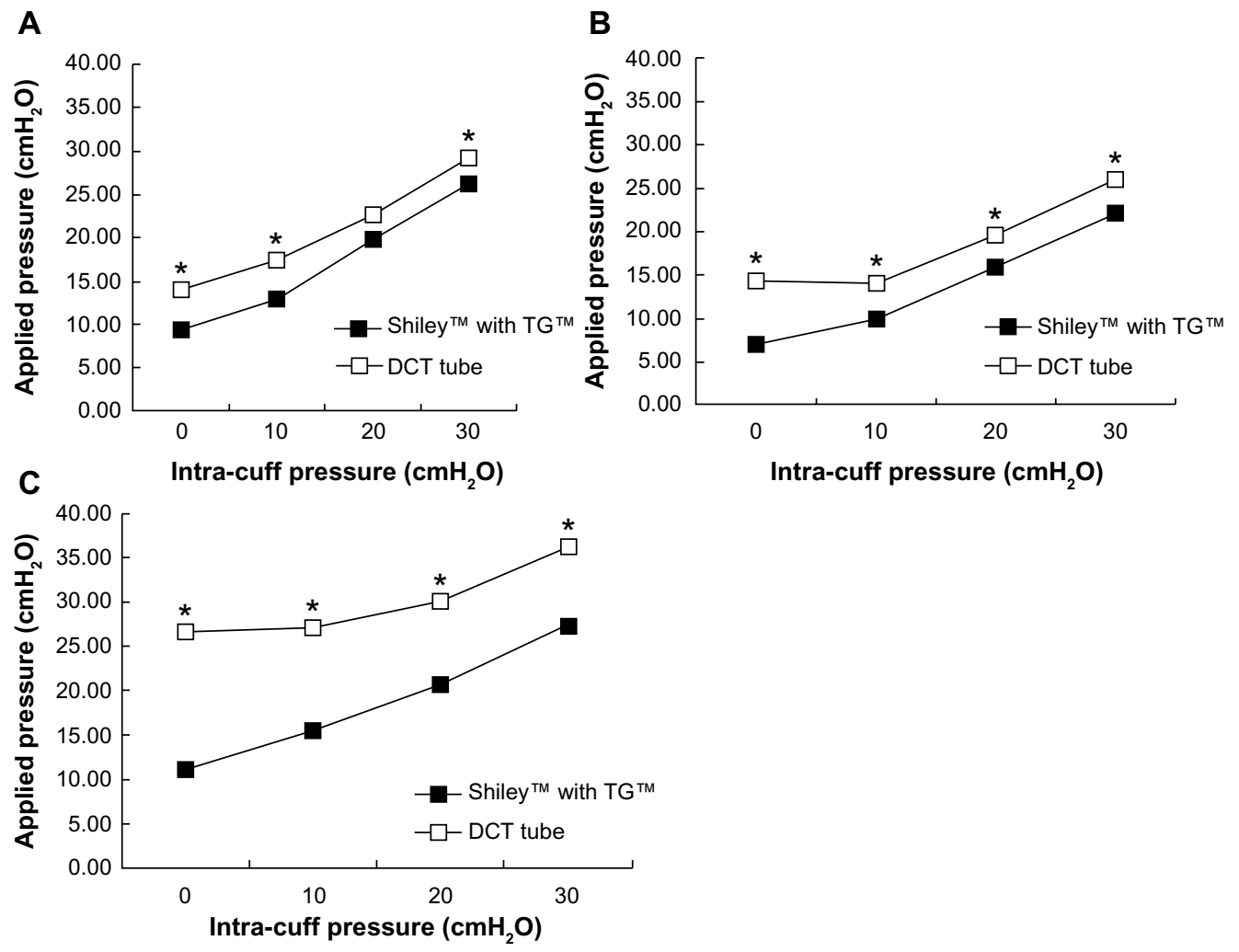

Figure 2 Mean pressure exerted on tracheal wall plotted against intra-cuff pressure. (A) Small tube size, (B) midrange tube size, (C) large tube size. Note: *Significance at the $P<0.05$ level.

Abbreviations: DCT, Disposable Cannula tracheostomy; TG, TaperGuard ${ }^{\mathrm{TM}}$. 

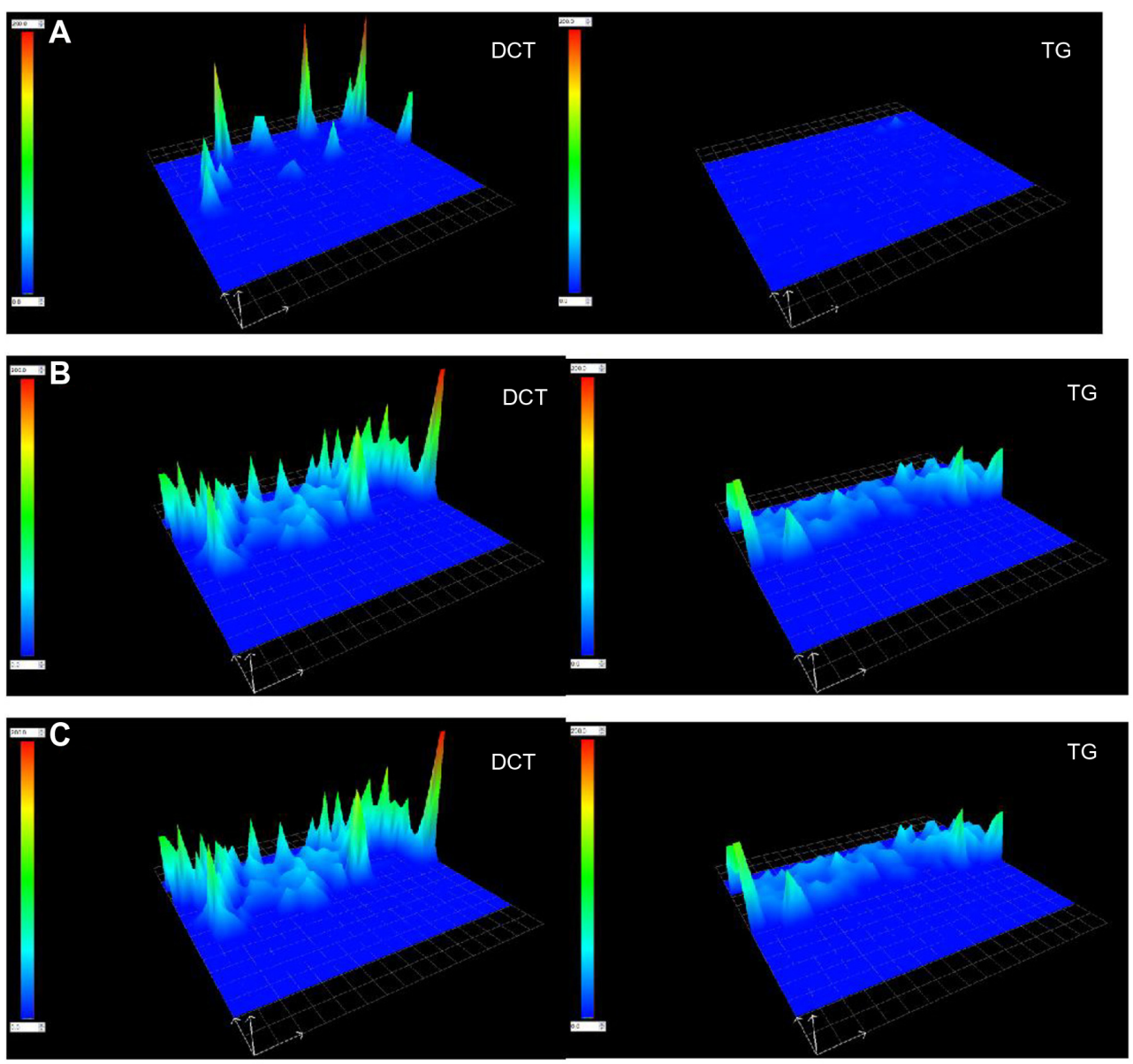

Figure 3 Pressure exerted on the model trachea with increasing amounts of intra-cuff pressure ([A] $\left.0 \mathrm{cmH}_{2} \mathrm{O} ;[\mathbf{B}] 20 \mathrm{cmH}_{2} \mathrm{O} ;[\mathbf{C}] 30 \mathrm{cmH}{ }_{2} \mathrm{O}\right)$ applied to the Shiley Disposable Cannula tracheostomy (DCT) tube cuff (left) and the Shiley ${ }^{\text {TM }}$ Flexible TaperGuard ${ }^{\text {TM }}$ (TG) cuff (right).

Notes: The height of the grid and the color changes depict the pressure values measured per the scale on the left (eg, dark blue, minimal height $=$ low pressure). Each image can be viewed as if the circular lateral wall pressure measurements were cut longitudinally and laid flat, with the bottom of the graph representing the distal portion of the trachea and the top the proximal portion. Because the model trachea is longer than the cuff, there is no pressure recorded in the distal trachea (ie, flat/dark blue) where there is no contact between cuff and trachea.

\section{Air seal}

The average volume of air leak past the two cuff types is listed in Table 2. Results demonstrated that the air leak was significantly lower for the Shiley ${ }^{\mathrm{TM}}$ Flexible tracheostomy tube with TaperGuard ${ }^{\mathrm{TM}}$ cuff than for the Shiley ${ }^{\mathrm{TM}}$ DCT tube with cylindrical cuff when both cuffs were inflated to an intra-cuff pressure of $25 \mathrm{cmH}_{2} \mathrm{O}$.

\section{Fluid seal}

The average volume of water leak past each cuff type is shown in Table 2. Results demonstrate that the Shiley ${ }^{\mathrm{TM}}$ Flexible tube with TaperGuard ${ }^{\mathrm{TM}}$ cuff had significantly less fluid leakage past the cuff than the Shiley ${ }^{\mathrm{TM}}$ DCT tube with cylindrical cuff for all tube sizes tested.

\section{Insertion force}

The average insertion force for each tube type is listed in Table 2. The force required to insert the Shiley ${ }^{\mathrm{TM}}$ Flexible tracheostomy tube with TaperGuard ${ }^{\mathrm{TM}}$ cuff was $40 \%$ less than that needed to insert the Shiley ${ }^{\mathrm{TM}}$ DCT tube with cylindrical cuff. Insertion force was significantly lower with the TaperGuard ${ }^{\mathrm{TM}}$ cuff for each tube size tested.

\section{Discussion}

The cuff on a tracheostomy tube seals the tracheal lumen, permits the maintenance of airway pressure and tidal volume during mechanical ventilation, and guards against aspiration. A known hazard of the inflated cuff is tracheal damage caused by pressure transmitted to the tracheal wall that exceeds mucosal perfusion pressure. ${ }^{11}$ Current standard practice includes the maintenance of intra-cuff pressure between 20 and $30 \mathrm{cmH}_{2} \mathrm{O}$, which will seal the airway to prevent aspiration while minimizing damage to the trachea. The intra-cuff pressure range used in the study was 0 to $30 \mathrm{cmH}_{2} \mathrm{O}$, which is considered clinically relevant. ${ }^{12}$ 
Table 2 Cuff performance data

\begin{tabular}{|c|c|c|c|c|c|c|}
\hline \multirow[t]{2}{*}{ Size $(\mathrm{mm})$} & \multicolumn{2}{|c|}{ Mean air leak $(\mathrm{mL})$} & \multicolumn{2}{|c|}{ Mean fluid leak (mL/h) } & \multicolumn{2}{|c|}{ Mean insertion force (kgf) } \\
\hline & DCT & TG & DCT & TG & DCT & TG \\
\hline 6.0 & $120.3(58.2)$ & $9.1(7.6)^{*}$ & $828.9(964.7)$ & $4.4(15.5)^{*}$ & $0.250(0.06)$ & $0.119(0.06)^{*}$ \\
\hline 7.5 & I I $9.4(89.7)$ & $11.3(10.5)^{*}$ & $928.9(651.9)$ & $2.8(5.3)^{*}$ & $0.683(0.19)$ & $0.370(0.13)^{*}$ \\
\hline 10.0 & I $63.8(89.9)$ & $16.2(16.6)^{*}$ & $1070.9(618.4)$ & $2.1(8.6)^{*}$ & $0.496(0.11)$ & $0.374(0.27)^{*}$ \\
\hline Average & | $34.5(82.4)$ & $12.2(12.4)^{*}$ & $943.0(759.1)$ & $3.1(10.6)^{*}$ & $0.476(0.22)$ & $0.298(0.2 \mathrm{I})^{*}$ \\
\hline
\end{tabular}

Notes: Data are presented as mean (standard deviation). *Significance at the $P<0.05$ level.

Abbreviations: DCT, Disposable Cannula tracheostomy; kgf, kilogram force; TG, TaperGuard TM.

In the current study, for each tube size tested, the average pressure exerted on the lateral wall of the model trachea was lower for the Shiley ${ }^{\mathrm{TM}}$ Flexible tracheostomy tube with TaperGuard ${ }^{\mathrm{TM}}$ cuff than for the Shiley ${ }^{\mathrm{TM}}$ DCT tube with the cylindrical cuff. This is likely due to the DCT cuff being larger in diameter than the tracheal model, which is one of the core design features universal to all HVLP cuffs. This oversized cuff, when constrained within the patient's trachea, will develop folds and channels. These folds and channels create localized contact points. The TaperGuard ${ }^{\mathrm{TM}}$ cuff has been designed through its geometry, materials, diameter, and wall thickness to minimize folds and channels while providing more flexibility to the cuff material. This combination allows for increased surface-to-surface contact between the cuff and the wall of the trachea, resulting in a more even distribution of forces and a reduction in pressure spikes. The high-pressure spikes elevate the average lateral wall pressure values for the cylindrical-shaped cuffs.

Intra-cuff pressure did not equal lateral wall pressure at every contact point and, moreover, the measured lateral wall pressure was higher than the intra-cuff pressure at many points of contact. At an intra-cuff pressure of zero, pressure was transmitted to the lateral wall of the model trachea because the deflated cuff profile could be bigger than the diameter of the model trachea. The TaperGuard ${ }^{\mathrm{TM}}$ cuff has a lower cuff profile when deflated than the cylindrical-shaped cuff. When HVLP cuffs are inflated to atmospheric pressure, the cuff diameter can be $120 \%-150 \%$ of the internal tracheal diameter. ${ }^{13}$ Even when an HVLP cuff is deflated to a subatmospheric pressure and the cuff fully deflates, the surface topography of the cuff may be such that portions of the cuff may still make contact with the tracheal wall and transmit pressure, as was observed during testing.

The pressure distribution of the cuff on the lateral tracheal wall was not uniform or homogeneous for either cuff type, as depicted by the intermittent appearance of red- and greentipped spikes that indicate higher pressure points (Figure 3). The TaperGuard ${ }^{\mathrm{TM}}$ cuff has a more homogeneous and lower pressure distribution than the DCT cuff.
As in this study, Li Bassi et $\mathrm{al}^{7}$ also observed points at which the pressure exerted on the lateral tracheal wall was higher than the intra-cuff pressure and suggested that this may be due to the formation of folds pressing on the trachea. They proposed that the portion of the tracheal wall that abuts the cuff fold may be exposed to higher transmitted pressure due to tangential force exerted on a smaller contact area. ${ }^{7}$ This is common to all HVLP cuffs and is the result of the device design such that the cuff inflated to atmospheric pressure has a larger diameter than the internal tracheal diameter.

The TaperGuard ${ }^{\mathrm{TM}}$ cuff provides a more effective seal of the trachea ${ }^{9}$ with a smaller tracheal contact area. ${ }^{7}$ The TaperGuard $^{\mathrm{TM}}$ cuff forms a small band where the inflated cuff has a diameter equal to the trachea at a point between the oversized proximal and undersized distal portions of the cuff. This band of contact reduces the number of micro-channels and the associated passage of air and fluid leaking past the cuff. ${ }^{4}$ The leakage of secretions or gastric contents through these channels and into the lungs increases the risk for complications including ventilator-associated pneumonia. ${ }^{14} \mathrm{An}$ incomplete seal resulting in gas leakage can result in a failure to maintain positive end-expiratory pressure and hypoventilation. ${ }^{15}$ In a bench study using a model of the trachea, Madjdpour et $\mathrm{al}^{4}$ demonstrated that an endotracheal tube with a taper-shaped cuff made from polyvinyl chloride (PVC) significantly improved air sealing compared to standard cylindrical-shaped cuffs. The cylindrical-shaped PVC cuff did not effectively seal the trachea, even at the high end of clinically accepted intra-cuff pressure (ie, $30 \mathrm{cmH}_{2} \mathrm{O}$ ), when measured by both sevoflurane concentration passing around the cuff and the ratio of expired tidal volume to inspired tidal volume. In a clinical study, when the two cuff types were compared during short-term use on surgical patients, the taper-shaped cuff demonstrated better protection against aspiration. ${ }^{16}$

Changing the patient's cuffed tracheostomy tube may cause irritation to the stoma due to the bulk of the deflated cuff material. The Shiley ${ }^{\mathrm{TM}}$ Flexible tracheostomy tube with its taper-shaped cuff, made from thinner material and having a smaller volume than the Shiley ${ }^{\mathrm{TM}}$ DCT tube cuff, 
requires less force when inserted into the simulated patient's stoma (Table 2) and, therefore, may cause less trauma to the patient.

Another enhancement to the Shiley ${ }^{\mathrm{TM}}$ Flexible tracheostomy tube is a transparent, soft PVC flange designed to conform to the patient's clavicle. The central portion of the flange has symmetrical windows and is offset to help reduce contact with the patient's skin. These changes in flange characteristics may improve the comfort of patients with tracheostomy tubes, many of whom have these devices in place for extended periods of time. The flange of the Shiley ${ }^{\mathrm{TM}}$ Flexible tracheostomy tube is constructed from a new non-di-(2-ethylhexyl)-phthalate (DEHP) PVC formulation. PVC is softened through the use of plasticizers of which DEHP is the most commonly used in tracheostomy tubes and many other medical devices. Health concerns related to the release of DEHP into biological fluids and tissues have been raised by the US Food and Drug Administration; ${ }^{17}$ the Ministry of Health, Labor and Welfare, Health, Canada; ${ }^{18}$ and the European Commission. ${ }^{19}$ As a precaution, DEHP has been removed from the Shiley ${ }^{\mathrm{TM}}$ Flexible tracheostomy tube and replaced with a citrate and dioctyl terephthalate-based plasticizer. Citric acid, a metabolite of plants and animals, and dioctyl terephthalate are widely used in food packaging, medical products, soft toys for children, and cosmetics and are not known to have any ill-effects on human health. ${ }^{20}$

\section{Study limitations}

The trachea model used in the bench testing was a rigid circular tube, while an actual trachea is non-circular and somewhat distensible. Therefore, the study conditions do not necessarily reflect what might happen in a clinical situation. In addition, the products were tested at approximately room temperature, while, when in clinical use, tracheostomy tubes are used at body temperature, which could impact device performance.

\section{Conclusion}

The Shiley ${ }^{\mathrm{TM}}$ Flexible tracheostomy tube with TaperGuard ${ }^{\mathrm{TM}}$ cuff offers several improvements compared to the Shiley ${ }^{\mathrm{TM}}$ DCT tube with a cylindrical-shaped cuff, including a tapered shape and thinner cuff. The results of this study demonstrate that, in a model trachea, the Shiley ${ }^{\mathrm{TM}}$ Flexible tracheostomy tube with TaperGuard ${ }^{\mathrm{TM}}$ cuff, when compared to the Shiley ${ }^{\mathrm{TM}}$ DCT tube with cylindrical cuff, exerted a lower average lateral wall pressure and a more evenly distributed pressure. In addition, it provided more effective fluid and air seals and required less force to insert.

\section{Disclosure}

Frances Haury, Seamus Maguire, and Korinne Jew all work for Covidien, the manufacturer of the Shiley ${ }^{\mathrm{TM}}$ tracheostomy tubes tested and discussed in this paper. The authors report no other conflicts of interest in this work.

\section{References}

1. Bernet V, Dullenkopf A, Cannizzaro V, Stutz K, Weiss M. An in vitro study of the compliance of paediatric tracheal tube cuffs and tracheal wall pressure. Anaesthesia. 2006;61(10):978-983.

2. Spiegel JE. Endotracheal tube cuffs: design and function. Anesthesiology News. 2010;36(8):51-58.

3. Carroll RG, McGinnis GE, Grenvik A. Performance characteristics of tracheal cuffs. Int Anesthesiol Clin. 1974;12(3):111-141.

4. Madjdpour C, Mauch J, Dave MH, Spielmann N, Weiss M. Comparison of air-sealing characteristics of tapered- vs cylindrical-shaped highvolume, low-pressure tube cuffs. Acta Anaesthesiol Scand. 2011;56(2): 230-235.

5. Pavlin EG, VanNimwegan D, Hornbein TF. Failure of a high-compliance low-pressure cuff to prevent aspiration. Anesthesiology. 1975;42(2): 216-219.

6. Young PJ, Rollinson M, Downward G, Henderson S. Leakage of fluid past the tracheal tube cuff in a benchtop model. Br J Anaesth. 1997; 78(5):557-562.

7. Li Bassi G, Ranzani OT, Marti JD, et al. An in vitro study to assess determinant features associated with fluid sealing in the design of endotracheal tube cuffs and exerted tracheal pressures. Crit Care Med. 2013;41(2):518-526.

8. Shiotsuka J, Lefor AT, Sanui M, Nagata O, Horiguchi A, Sasabuchi Y A quantitative evaluation of fluid leakage around a polyvinyl chloride tapered endotracheal tube cuff using an in-vitro model. HSR Proc Intensive Care Cardiovasc Anesth. 2012;4(3):169-175.

9. Zanella A, Scaravilli V, Isgrò S, et al. Fluid leakage across tracheal tube cuff, effect of different cuff material, shape, and positive expiratory pressure: a bench-top study. Intensive Care Med. 2011;37(2): 343-347.

10. Hess DR. Tracheostomy tubes and related appliances. Respir Care. 2005;50(4):497-510.

11. Seegobin RD, van Hasselt GL. Endotracheal cuff pressure and tracheal mucosal blood flow: endoscopic study of effects of four large volume cuffs. Br Med J (Clin Res Ed). 1984;288(6422): 965-968.

12. Bhardwaj N. Pediatric cuffed endotracheal tubes. J Anaesthesiol Clin Pharmacol. 2013:29(21):13-18.

13. Dullenkopf A, Gerber A, Weiss M. Fluid leakage past tracheal tube cuffs: evaluation of the new Microcuff endotracheal tube. Intensive Care Med. 2003;29(10):1849-1853.

14. Metheny NA, Clouse RE, Chang YH, Stewart BJ, Oliver DA, Kollef MH. Tracheobronchial aspiration of gastric contents in critically ill tube-fed patients: frequency, outcomes, and risk factors. Crit Care Med. 2006;34(4):1007-1015.

15. Tobin MJ, Jubran A, Laghi F. Fighting the ventilator. In: Tobin MJ, editor. Principles and Practice of Mechanical Ventilation. 3rd ed. Chicago, IL: McGraw Hill; 2013:1237-1258.

16. D'Haese J, De Keukeleire T, Remory I, Van Rompaey K, Umbrain V, Poelaert J. Assessment of intraoperative microaspiration: does a modified cuff shape improve sealing? Acta Anaesthesiol Scand. 2013;57(7): $873-880$.

17. US Food and Drug Administration (FDA) Center for Devices and Radiological Health. Safety Assessment of Di(2-ethylhexyl)phthalate (DEHP) Released from PVC Medical Devices. Rockville, MD: FDA Center for Devices and Radiological Health; 2001. Available from: http://www.fda.gov/downloads/MedicalDevices/.../UCM080457.pdf. Accessed March 5, 2015. 
18. di(2-ethylhexyl)phthalate (DEHP): Health Canada Expert Advisory Panel on DEHP in medical devices [web page on the Internet]. Final report. mindfully.org; 2002. Available from: http://www.mindfully.org/Plastic/ DEHP-Health-Canada1 1jan02.htm. Accessed February 9, 2015.

19. European Commission Scientific Committee on Medicinal Products and Medical Devices (SCMPMD). Opinion on Medical Devices Containing DEHP Plasticised PVC; Neonates and Other Groups Possibly at Risk from DEHP Toxicity. European Commission SCMPMD; 2002, Brussels, Belgium.
20. Babich MA, Versar Inc., Syracuse Research Corporation. Review of Exposure and Toxicity Data for Phthalate Substitutes. Bethesda, MD: US Consumer Product Safety Commission; 2010. Available from: http:// www.cpsc.gov/PageFiles/126546/phthalsub.pdf. Accessed March 5, 2015.

\section{Publish your work in this journal}

Medical Devices: Evidence and Research is an international, peerreviewed, open access journal that focuses on the evidence, technology, research, and expert opinion supporting the use and application of medical devices in the diagnosis, treatment and management of clinical conditions and physiological processes. The identification of novel devices and optimal use of existing devices which will lead to improved clinical outcomes and more effective patient management and safety is a key feature. The manuscript management system is completely online and includes a quick and fair peer-review system. Visit http://www. dovepress.com/testimonials.php to read real quotes from authors.

Submit your manuscript here: http://www.dovepress.com/medical-devices-evidence-and-research-journal 